\title{
0 poder simbólico e a distância entre os dois Brasis: o formal e 0 informal
}

\section{Symbolic power and the distance between two Brazils: the formal and the informal}

\section{esumo}

Nexte texto, examina-se a dimensão simbólica do discurso jurídico como construtor de realidades, entre os agentes institucionais ligados às profissões do trabalho social. Demonstra-se, assim, que as opiniões - tecnicamente fundamentadas - desses agentes transformam-se em pareceres que podem corroborar as decisões judiciais, contribuindo para a construção de concepções sociais a respeito da população. Ao mesmo tempo, analisam-se as formas diferenciadas de vivência da lei por um expressivo conjunto do corpo social brasileiro que experiencia uma subjetividade específica. Para tanto, estudam-se os aspectos que demarcam a separação entre a lei formal, de um lado, e os usos e costumes praticados cotidianamente pela maioria das pessoas, de outro. Por fim, examinam-se as razões pelas quais os brasileiros se reconhecem muito mais nas normas informais, estabelecidas pelas experiências grupais e aceitas pela maioria, do que nas leis formais. Essa legislação informalmente estruturada é reveladora da obediência a códigos implícitos, porque não legalizados oficialmente.

Palavras-chave: lei, poder simbólico, subjetividade, jeitinho brasileiro, discurso jurídico.

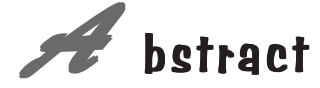

This paper examines the symbolic dimension of legal discourse as a constructor of realities, among the institutions linked to the professions of social work. It demonstrates that the technically based opinions of these agents are transformed into reports that can corroborate judicial decisions, contributing to the construction of social concepts about the population. At the same time, it analyzes the distinct forms of experiencing the law among an expressive portion of Brazilian society that have a specific subjectivity. To do so, it studies the factors that mark the separation between formal law on one hand, and the uses and customs practiced daily by the majority of people, on the other. Finally, it examines the reasons for which Brazilians identify much more closely with informal norms, established by experiential groups and accepted by the majority, than with formal laws. This informally structured legislation reveals the obedience to implicit codes, not officially legalized.

\section{Mauro Gaglietti}

Key words: law, symbolic power, subjectivity, Brazilian way, juridical speech.
Doutor em História pela PUCRS.

Professor no Instituto de Filosofia e Ciências Humanas - IFCH, Universidade de Passo Fundo - UPF. 
$n$ este texto discutem-se as lutas simbólicas praticadas pelos profissionais do social e a articulação com o discurso jurídico como construtor de realidades. Além disso, examinam-se as práticas sociais de grande parte da população brasileira que expõem a existência de formas diferenciadas de vivência da lei. A maioria das análises e opiniões vincula esse fenômeno à "desordem" e à "desobediência" às leis formais. A par disso, acredita-se aqui que é possível analisar a dinâmica do funcionamento de um grupo social com base no estabelecimento de vários modelos interpretativos. Dessa maneira, pode-se encontrar operando, subjacente às práticas sociais, o princípio de uma economia mora (THOMPSON, $1979)^{1}$. Tal conceito pode auxiliar na medida em que oferece a possibilidade de outras interpretações a práticas sociais exercidas pela sociedade nacional. Tal modalidade interpretativa vai de encontro àquelas narrativas que caracterizam as práticas sociais como manifestação da anomia e da inépcia social brasileira (SOUZA, 1996) ${ }^{2}$.

Os profissionais do social (COSTA, 1998) estabelecem interfaces, em suas práticas cotidianas, com as esferas jurídica e política. Assim, vivenciam inúmeros problemas que, de certa forma, referemse a fatores concernentes às dimensões subjetivas as relações entre profissionais que atuam na área social - e às suas atuações nas instituições. Talvez se possa falar aqui, para exemplificar o caso, na "construção social da Psicologia Jurídica no Brasil"'(BERNARDI, 1999, p. $21-24)^{4}$, toda vez que as fronteiras entre Serviço Social e Psicologia, enquanto olhares que decifram a demanda institucional, revelarem-se tênues, não se sustentando nos parâmetros teóricos e metodológicos das respectivas disciplinas. Dessa maneira, constata-se que as formas simbólicas têm uma dimensão histórica que está expressa nos relatórios, nos laudos e pareceres, que circulam como um sentido em si e como meio de propagação de concepções adotadas sobre as pessoas e suas relações. Situações impactantes de uma realidade social desigual e injusta são mostradas ao Judiciário pelos saberes (e dizeres) do assistente social judiciário e do psicólogo judiciário ${ }^{5}$. Desse modo, são testemunhas oculares de um tempo que se vai diferenciando, ora pela inclusão de novos atores, ora pela mudança de enfoque das práticas, ora pela escassez de recursos e de pessoas. Os saberes que são próprios do campo jurídico formam conteúdos advindos da legislação (regras, normas, dogmas e conceitos oriundos do Direito), de regras institucionais de administração da entidade, de regras informais do relacionamento institucional e de outros saberes construídos sobre o mesmo objeto de intervenção (ou de compreensão e encontro) e que circulam nas relações e nas peças processuais. As opiniões, tecnicamente fundamentadas, transformam-se em pareceres que podem corroborar as decisões judiciais nos casos, contribuindo para a construção e sustentação de concepções sociais a respeito da população e de seus problemas.

É possível que a ascensão do "social", na agenda das lutas simbólicas, tenha colaborado para que ocorresse um certo redimensionamento da relação saber/poder. Nesse caso, há uma espécie de concorrência, por entrelaçamentos e interpenetrações, entre os

[...] saberes e práticas explicativos, compreensivos e classificatórios da Pedagogia, da Psicologia, da Biologia, da Psicanálise, da Psiquiatria, da Medicina, do Direito, do Serviço Social, num incessante jogo de forças, num incessante exercicio de poderes, e em contextos institucionais diversos (COSTA, 1998, p.223).

\section{realidade social desigual e injusta}

são mostradas ao Judiciário pelos

\section{saberes (e dizeres) do assistente}

\section{social judiciário e do}

$$
\text { psicólogo iudiciário. }
$$

Se, por um lado, a relação - subjetiva e institucional - existente entre os profissionais de saberes diferentes que atuam na "área social" é dada mediante a luta pela classificação do "social", por outro, entre os profissionais de idêntica formação acadêmica ocorre a constituição de um "campo" de atuação que, de alguma for-

ma, funciona a partir de determinadas regras (GAGLIETTI, 1999, p. 83-91) $)^{6}$.

Examinam-se, particularmente, os aspectos profissionais dos operadores jurídicos, para se tentar interpretar, por homologias, suas particularidades e possíveis conexões com a ação social dos demais profissionais que trabalham com o social. Portanto, é na relação existente entre os profissionais do Direito que se pode buscar a noção de campo jurídico ${ }^{7}$. Tal conceito sociológico procura explicar a concorrência que se estabelece entre os operadores jurídicos, cada um reivindicando para si a interpretação mais legítima de um conjunto de textos que consagram uma visão "justa" do mundo social. O campo jurídico tende a funcionar como um sistema ordenado de atitudes, na medida em que a coesão dos $h_{a b i t u s}{ }^{8}$, - espontaneamente orquestrados - dos intérpretes é ampliada e reforçada pela prática hierarquizada de um corpo de 
profissionais. São eles que, por terem autoridade de promover a resolução regulada dos conflitos, internalizam e põem em execução os vereditos.

É possível afirmar que o direito tem raízes na coesão social dos seus respectivos intérpretes. Essa coesão confere à razão jurídica a aparência de um fundamento transcendental (sem história) e estimula a crença na sua capacidade de ordenamento social. Nesse contexto, é traçado o modelo de conduta a ser assumido pelo profissional do Direito, o perfil desejável, aceito socialmente e, portanto, necessário para que ele esteja à altura da função que se propõe a exercer. É também nesse âmbito que se definem as relações de poder entre os "clientes" (leigos) e os "especialistas do espaço judicial".

Facultar ao corpo de doutrinas e regras um fundamento transcendental é tentar colocá-las a salvo da interferência dos fatores históricos, psicológicos, sociológicos e, sobretudo, de quaisquer usos sociais práticos de que tais normas possam ser objeto. No entanto, a própria definição do campo jurídico por parte das ciências sociais demonstra que tal tentativa é, no mínimo, inócua. Para o sociólogo francês Pierre Bourdieu (1989), o campo jurídico é o espaço onde ocorrem intensas relações sociais conflituosas, na forma de um debate juridicamente regulado entre os profissionais que, por meio de uma procuração, atuam em nome dos segmentos sociais. Esses profissionais têm em comum o fato de participarem de um jogo jurídico bem delineado, composto por regras formais e informais. Em tal espaço, é selado um pacto segundo o qual os conflitos só podem ser resolvidos segundo as regras e as convenções do campo jurídico. Depreende-se daí a aceitação tácita de que o modo de expressão e de discussão a ser adotado implica a renúncia à violência física, à injúria e à difamação (violência simbólica).

O poder, no campo jurídico, pode ser medido pela competência jurídica, que dá o seu aval aos integrantes desse espaço social. Portanto, é impraticável pensar o campo jurídico sem a atuação dos operadores jurídicos como detentores exclusivos da produção e da comercialização dos serviços jurídicos. Investidos da legitimidade que tal monopólio lhes confere, os profissionais tendem a acreditar numa efetiva resolução dos conflitos. Estes, porém, não são resolvidos na sua totalidade: o que ocorre é apenas uma decisão sobre um litígio. $O$ veredito é a expressão concentrada da luta entre pontos de vista particulares (cognitivos e avaliativos), os quais coincidem num aspecto: o reconhecimento social da autoridade que anuncia a decisão.
A palavra do juiz possui eficácia simbólica, pois é enunciada em nome de todos e perante todos. Essa magia é bem sucedida porque o Direito consagra a ordem estabelecida pelo Estado ao reproduzir e garantir, simbolicamente, a coesão social por meio de um sistema hierarquizado de normas. Sem dúvida, o Direito é a forma por excelência do poder simbólico ${ }^{9}$, uma vez que o discurso jurídico, dadas as condições histórico-sociais necessárias, é capaz de criar as coisas que nomeia. A força desse tipo de discurso reside no efeito que produz: o de "fazer" o mundo social quando decide sobre este.

$\mathrm{Na}$ década de 1980, o professor Luis Alberto Warat (1995) já chamava atenção para alguns aspectos da "esfinge discreta" da ciência do Direito. A capacidade de "fazer crer", potencializada pelos diversos usos sociais das "ciências jurídicas", pode ser explicada, de acordo com Warat, pela competência simbólica do Direito em escamotear a genealogia e o funcionamento institucional do seu discurso. Essa dimensão simbólica adquirida pelo Direito, ao simular lingüisticamente sua própria unidade, constrói uma esfera ilusória da igualdade de todos perante a lei. Tratase, assim, de uma violência simbólica, por ser erigida em uma sociedade sem conflitos - ao menos na aparência e na crença de tal aparência -, sem vontades, sem diferenças culturais e sem tempo histórico.

Os mecanismos ilusórios limitam ou canalizam os desejos, oferecendo um simulacro de sua satisfação ou concretização. Dessa forma, colocam em funcionamento o sistema dominante das representações sociais e jurídicas, constituindo aquilo que se convencionou chamar de Estado. Nesse contexto, o Estado encarna a vontade geral, articula a ordem e a moral da nação e organiza o monopólio legítimo da violência. $\mathrm{Na}$ aparência, o Estado não é um produto humano, pois o simulacro ou feitiço mencionado logra uma obediência civil de tamanha ordem que os homens não parecem obedecer a outros homens, e, sim, fundamentalmente, a determinados valores sociais prescritos pela lei ou por regras informais. O conflito, dentro dessa ordem, é sempre encarado como o desvio de uma normalidade, ou seja, como uma transgressão do regramento jurídico. Desse modo, conforme explica Warat (1995, p. 59-60), "a razão de Estado fica identificada com a racionalidade do saber jurídico e da lei positiva como uma forma de impor-nos interesses e desejos legalizados, quer dizer, que estes passam a ser os mesmos desejos e interesses que outorgam consistência simbólica ao Estado". 
Esse feitiço apontado anteriormente está implícito na lógica das normas jurídicas, uma vez que estas têm a capacidade de incorporar na lei todas as dimensões do poder do Estado. Assim, atribui-se à ordem legal uma obrigatoriedade quando, na verdade, as normas jurídicas estão sujeitas a oscilações provocadas pelos resultados das disputas no campo social. É nesse terreno que se define quem encarna a "Razão". Tal processo se efetiva à medida que a linguagem jurídica concede a si mesma a autoridade de nomear as coisas empregando palavras distintas das designações utilizadas pelo chamado "senso comum". Então, ocorre uma divisão dos espaços mentais em razão do desvio provocado por esse significado distinto. Tal divisão vem a materializar, de certa forma, espaços sociais diferentes que atribuem sentido e valor desigual às diferentes expressões empregadas pelos leigos e pelos operadores jurídicos.

Bourdieu explica que o espaço judicial funciona como um lugar neutro, "que opera uma verdadeira neutralização das coisas em jogo por meio da 'des-realização' e da distanciação implicadas na transformação da defrontação directa dos interessados em diálogo entre mediadores". Para Bourdieu (1989, p. 227-228),

[...] os agentes especializados, enquanto terceiros - indiferentes ao que está diretamente em jogo (o que não quer dizer desinteressados) $e$ preparados para apreenderem as realidades escaldantes do presente atendo-se a textos antigos e a precedentes confirmados - introduzem, mesmo sem querer nem saber, uma distância neutralizante a qual, no caso dos magistrados pelo menos, é uma espécie de imperativo da função que está inscrita no âmago dos 'habitus'.

Em primeiro lugar, destaca-se que a autoridade jurídica, em certos casos, pode ser exercida numa esfera social relativamente independente e impermeável em relação às pressões externas, da sociedade civil. Nesse caso, ocorre, a partir da ação legítima do Estado, a combinação do uso da violência simbólica com o emprego da força física. Em segundo lugar, verifica-se que existe um tipo específico de divisão do trabalho jurídico que gira em torno da concorrência pelo monopólio do direito de dizer o Direito.

Essa divisão do trabalho entre os profissionais do Direito é condicionada pela função que ocupam e pelo maior ou menor distanciamento que mantêm em relação aos leigos. Com base nas prerrogativas e vantagens que lhes são conferidas pelo lugar que ocupam, tais profissionais garantem a sua participação no jogo concorrencial, reproduzindo a lógica que o consagra. É essa lógica que formata a eqüidade dos princípios, a coerência das formulações e o rigor da aplicação das normas por parte dos agentes e instituições do campo jurídico.
O sistema de normas jurídicas apresenta-se a todos como algo totalmente dissociado das relações de poder econômico, político e cultural. Essa separação é, ao mesmo tempo, a causa maior e a principal conseqüência da secessão social entre os leigos, que clamam pela igualdade social, e dos profissionais do Direito, que desenvolvem um trabalho contínuo. Tal trabalho sistemático tem promovido a ação racional desses agentes, o que, de certa forma, vem colaborando para o aprofundamento da separação que se instalou entre profissionais e leigos. É também esse processo que autoriza apenas os primeiros a interpretarem legitimamente as normas jurídicas e a própria ordem social.

A particularidade da interpretação de textos jurídicos reside na sua adequação à dimensão operacional prática. Nesse caso, a perpetuação da sua eficácia dá-se em função de uma certa limitação da sua própria autonomia. Assim, nos escritos jurídicos estão presentes elementos de força simbólica em estado latente, partem daí os conflitos constantes entre as distintas interpretações. O limite dessas lutas que estruturam o campo jurídico é a decisão judicial, que se apresenta como resultado natural de uma interpretação apoiada em fontes que lhe conferem autoridade.

A despeito do vínculo que existe entre a eficácia das interpretações e a sua aplicabilidade, o campo jurídico possui uma lógica de funcionamento que, muitas vezes, ignora essa ligação. Essa lógica implica a aceitação de pressupostos que independem da experiência de vida. A evidência deste apriorismo está na retórica da universalização e da neutralização que caracterizam a língua jurídica. A retórica jurídica constrói um sujeito universal, imparcial e objetivo, que está acima da experiência da vida. Além disso, empenha-se em mostrar a existência de um consenso ético, ocultando a pluralidade social.

A autoridade dos atos jurídicos singulares é amparada pelo cânone jurídico, centro que fundamenta todas as decisões. Os operadores jurídicos estão ligados, de uma forma ou de outra, à teoria do direito e aos especialistas do direito constitucional por uma cadeia de legitimidade que justifica seus atos toda vez que eles invocam, por uma questão de costume e/ou estratégia consciente, uma argumentação extraída de textos consagrados. Assim também procedem os profissionais de outros campos sociais.

De acordo com Bourdieu (1989, p. 221-222),

Pertence aos juristas, pelo menos na tradição dita romano-germânica, não o descrever das práticas existentes ou das condições de aplicação prática das regras declaradas conformes, mas sim o 'pôr-em-forma' dos princípios e das regras envolvidas nessas práticas, elaborando um corpo sistemático de regras assente em princípios racionais e destinados a ter uma aplicação universal. 
Bourdieu afirma que os juristas "procuram a revelação do justo na letra da lei, e do modo de pensamento lógico pois pretendem pôr em prática o método dedutivo para produzirem as aplicações da lei ao caso particular". Eles desejam, no dizer do sociólogo, "criar uma 'ciência nomológica' que enuncie o dever-ser cientificamente, como se quisessem reunir os dois sentidos separados da idéia de "lei natural"". Praticam, desse modo, "uma exegese que tem por fim racionalizar o direito positivo por meio de trabalho de controle lógico necessário para garantir a coerência do corpo jurídico e para deduzir dos textos e das suas combinações conseqüências não previstas, preenchendo assim as famosas 'lacunas' do direito" (BOURDIEU, 1989, p. 221-222).

Os profissionais que colocam, no centro de suas preocupações, os casos concretos orientam o Direito para um sentido pragmático, que tenta dar conta dos dados imediatos, das situações do cotidiano. Os "teóricos", por sua vez, tendem a fechar-se no âmbito de um rigorismo racional, de onde são abstraídos outros índices, inclusive as práticas sociais, eles asseguram a sobrevivência do campo jurídico, ao propiciar as condições necessárias à luta concorrencial com os demais operadores do Direito. No que diz respeito aos juristas - pelo trabalho de racionalização e de formalização a que submetem o corpo de regras -, promovem a assimilação de um conjunto sistemático de princípios e normas, garantindo a sua coerência ao longo do tempo. Assim, os juristas oferecem aos juízes subsídios que lhes permitem fundamentar os seus vereditos no cânone jurídico.

Não se trata de negar a competência do trabalho de decodificação, que, ao incorporar-se no seu objeto, viabiliza e estimula a transformação deste. Ao mesmo tempo, não se pode ser refém da representação exagerada da atividade jurídica a que procedem determinados operadores, os quais argumentam que a "ciência jurídica" é definida por um método dedutivo, que procura explicar o caso particular a partir de uma regra geral. É preciso levar em conta que a regra projetada numa situação pregressa nunca pode ser transposta sem mediações a um novo caso, porque jamais há dois casos perfeitamente idênticos.

Via de regra, a interpretação de uma norma não é um ato isolado do magistrado, que, preocupado em ampararse nos códigos canônicos, age com o objetivo de aplicar a regra ao pé da letra. Pelo contrário, o veredito é resultado da luta simbólica entre profissionais dotados de competências técnicas e sociais distintas. O significado real da conquista da hegemonia na interpretação de uma regra não está no maior rigor ou fidelidade de um dos intérpretes à dogmática jurídica. Trata-se, isto sim, de uma equação complexa, em que estão em jogo diferentes forças simbólicas e diversas visões do mundo. Então, a decisão judicial se deve mais às atitudes éticas dos agentes do que às normas puras do Direito.
Por fim, destaca-se a relatividade do efeito - quase mágico - de criar realidades a partir da força do discurso jurídico. $\mathrm{Na}$ verdade, existem condições sociais que, de alguma forma, limitam a eficácia do poder de nomeação do Direito. As representações do mundo social por parte dos agentes são responsáveis, até certo ponto, pela construção de tal mundo. Essas formulações mentais contribuem para produzir o mundo, mas dentro dos limites da sua correspondência com estruturas preexistentes. Portanto, o efeito propriamente simbólico das representações - dos esquemas de percepção e de apreciação -, que estão presentes na origem da construção do mundo social, é o de universalizar a prática oficial. Entretanto, não é menos verdade que a vontade de transformar o mundo passa pela transformação das palavras utilizadas para nomeálo. Ao descobrir novas maneiras de dizer o Direito, produzem-se novas categorias de percepção e de apreciação, introduzindo uma visão inusitada das divisões e das distribuições sociais. Mas, para que isso tenha algum resultado efetivo, essa vontade de transformar o mundo precisa estar amparada, em parte, em previsões bem fundamentadas na realidade.

Concluindo, se compararmos o campo jurídico com as demais esferas sociais que também conferem ao mundo uma dimensão social e simbólica (arte, ciência, literatura), aquele é o que possui menor grau de autonomia. Talvez isso se deva ao fato de que as mudanças externas têm conseqüência direta no campo jurídico e de que os conflitos nesse terreno sofrem muita influência dos fatores externos no momento da sua resolução. Muitas vezes, o campo jurídico é permeado pela variação das relações de força presentes nas demais esferas sociais. Isso ocorre porque a posição, mais ou menos relevante, dos diferentes operadores do Direito no interior do seu campo depende do lugar ocupado, na esfera política, pelos grupos cujos interesses estão mais diretamente ligados à área do Direito em que atuam aqueles profissionais (Direito do Trabalho, Direito Civil, Direito Administrativo, Direito Tributário, Direito Penal, etc.).

De certo modo, o que é válido para o âmbito de atuação dos operadores jurídicos também o é para os demais profissionais cuja atuação pauta-se pela dimensão social. Isso se deve, em parte, ao fato de existir, em cada grupo profissional, uma coesão social decorrente da idêntica formação acadêmica, que condiciona uma determinada interpretação do mundo e das formas de exercício e de reprodução do poder. Essa coesão confere à razão profissional a aparência de um fundamento transcendental e estimula a crença na sua capacidade de ordenamento social. Assim, o "campo" é o espaço, em cada área profissional, onde ocorrem relações sociais de intenso conflito, na forma de um debate regulado, por regras formais e informais, entre os agentes que, por meio de uma "procuração" simbólica, atuam em nome dos segmentos sociais 
que julgam representar (GAGLIETTI, 2003, 2005). A expressão maior desse processo revela-se na elaboração das opiniões tecnicamente fundamentadas. Tais formulações convertem-se em pareceres capazes de endossar as decisões judiciais, contribuindo para a construção e a sustentação de concepções sociais a respeito da população e de problemas enfrentados por esta.

\section{A relaçăo entre leis e o seu cumprimento (ou não) pelo brasileiro}

Entende-se que a descrença nas leis vincula-se, prioritariamente, à descrença nos poderes Legislativo, Executivo e Judiciário, que deveriam reger a vida pública nacional. Constata-se, por um lado, que a sociedade brasileira, de uma maneira geral, não prima pelo cumprimento de suas leis formais. Por outro, nota-se que é preciso reconhecer a especificidade da sociedade nacional no tocante à articulação da lei, que assume feições diferenciadas daquelas assumidas no projeto liberal e moderno, orientador do funcionamento de grande parte das sociedades ocidentais contemporâneas ${ }^{10}$.

No Brasil tem-se, ao que parece, a articulação específica de uma outra relação com as leis ${ }^{11}$. DaMatta (1992) desmistifica a concepção da nossa sociedade como moderna, ancorada em princípios liberais com o Estado, efetivando, ao menos aparentemente, a demarcação dos assuntos pertinentes ao interesse comum e ao interesse particular. Suas análises desmistificam também os estudos que a concebem exclusivamente como tradicional e holista. Assim, produziu-se no Brasil uma articulação entre a sociedade e a nação com os brasileiros interpretando e vivenciando a realidade nacional, orientados por esses dois códigos simultaneamente, ou seja, adotando o código individualista e igualitário da nação moderna e o código dos valores holistas e hierárquicos das sociedades tradicionais ${ }^{12}$.

Pode-se entender, dessa maneira, a sociedade nacional como resultante da hibridização da modernidade com o patrimonialismo, produto da articulação de um sistema liberal e patrimonial, no qual a concepção de indivíduo e seus pressupostos liberais encontrase vinculada às concepções do patriarcalismo ${ }^{13}$. Assim, as relações sociais no Brasil estariam vinculadas à convivência de uma incipiente implantação do liberalismo, amalgamada à herança patrimonialista herdada da colonização por- tuguesa. DaMatta (1992, p. 202) caracteriza o universo social brasileiro por meio da ação dos mecanismos que permitem a junção do impessoal, do anônimo e do injusto com o pessoal:

\section{A sugestão foi a de que o Brasil fica situado a meio caminho: entre a hierarquia e a igualda- de; entre a individualização que governa o mun- do igualitário dos mercados e dos capitais e o código das moralidades pessoais, sempre reple- to de nuanças, gradações, e marcado não mais pela padronização e pelas dicotomias secas do preto e do branco, de quem está dentro ou fora, do é ou do não é, mas permitindo mais uma di- ferença e uma tonalidade.}

Dessa forma, o envolvimento dos membros da sociedade brasileira nos espaços comuns e políticos encontrase restrita a uma pequena parcela da população. Por decorrência, as tentativas de reconhecimento - no sentido de identificação - pela utilização desses espaços encontram-se frustradas e outros mecanismos foram acionados, objetivando suprir essa função, tais como a valorização dos laços afetivos e de parentesco que redundam na construção de redes de sociabilidade diferentes das produzidas pelas sociedades ocidentais. Isso quer dizer que se faz necessário interpretar os processos identificatórios que produzem modos de subjetivação diferenciados de conformação da subjetividade privatizada, associada à ordem moderna.

Dito isso, pode-se analisar a sociedade brasileira contemporânea entendendo que, dada a peculiaridade do nosso desenvolvimento socioeconômico e histórico, desenvolveuse uma distância muito grande entre as práticas sociais e a representação da nação, encarnada na Constituição e no aparato estatal. Nesse sentido, constata-se a existência de uma separação entre a lei formal e os usos e costumes praticados cotidianamente pela maioria da população, ou seja, as leis no Brasil receberam e recebem um tratamento da ordem do formal (o estabelecido na Constituição, por exemplo) e da ordem do informal (o estabelecido nas normas e regras construídas no dia a dia).

No Brasil, é comum as comunidades criarem regras e normas informais, estabelecidas pelas experiências grupais e aceitas pela maioria da população, porque nelas se reconhece muito mais do que nas leis formais. Essa legislação infor- 
mal revela, de certo modo, a obediência a códigos implícitos, porque não legalizados oficialmente.

Para interpretar tal paradoxo brasileiro, Souza (1999) formula duas hipóteses: a primeira diz respeito à existência de traduções nacionais do contrato social liberal moderno, particularmente, do princípio da igualdade; a segunda refere-se à existência de formas específicas de vivência das leis, com a produção e utilização de mecanismos diferenciados, como, por exemplo, a elaboração de códigos informais, que deslocam, para outro espaço e práticas, a articulação da lei. A autora assinala (SOUZA, 1999, p. 78) que

[...] teríamos no país o estabelecimento de um contrato social, não no molde liberal, orientador das sociedades modernas, mas sim, contratos sociais (e podemos entendê-los assim, pois têm força de lei), estabelecidos entre duas ou mais pessoas que respeitam essas normas. Assim, as regras particulares, erigidas por esses contratantes, podem generalizar-se, assumindo o caráter de leis, passando a orientar e a produzir subjetividades que nelas se reconheçam, explicando a "moda nacional" do contrato social, a capacidade e, mesmo, a necessidade do país de assujeitamento.

No Brasil há um Estado cuja máxima orienta o modelo liberal do contrato social e regula as relações entre este e a sociedade civil, sendo apregoado pelos detentores do poder econômico e social como que orientando suas funções. Todavia, na maior parte das situações, essa máxima não é praticada. Essa situação gerou e gera a descrença no poder público e a produção de práticas sociais que buscam ocupar esse vazio institucional. Por sua vez, essas práticas produziram e produzem um conjunto de leis informais, criadas por meio de contratos pessoais, sem a mediação do aparato estatal, constituindo um verdadeiro código de regras e normas que regem, na prática, nossa sociedade. Entretanto, verifica-se que a contradição não se estabelece somente entre regras informais e práticas cotidianas de um lado, e leis formais, de outro, mas também no interior das próprias práticas formais e informais.

A conclusão provisória a que se pode chegar, mediante o exposto é a de que, na sociedade brasileira, a produ- ção de subjetividade é marcada por diferentes maneiras de encarar e de vivenciar a prática da lei e, conseqüentemente, por diversos modos de representar e de exercitar o contrato social e o princípio da igualdade A forma moderna e liberal é a que se encontra prescrita na Constituição Federal aprovada em 1988 e que explicita a defesa do papel do Estado e dos governantes como figuras públicas que têm de dar conta da transparência das suas decisões, colocando o bem público acima dos seus interesses. Uma outra forma existente no país, seria marcada pelo estabelecimento de regras e normas informais que se inscrevem em diferentes modalidades de estabelecer e viver o "contrato social" e o "princípio da igualdade", sendo explicitadas pelas práticas sociais.

Observa-se que as regras informais funcionam para todos, independentemente da situação social. Entretanto, a articulação da demanda pela igualdade - um dos princípios do contrato social - no Brasil, expressa pelo excesso afetivo e intimista e pela negação por meio das disparidades sociais (distribuição de renda), funciona como um sintoma, oferecendo uma solução de compromisso ao conflito estabelecido entre a demanda por um país moderno e a demanda voltada à manutenção do país na condição patriarcal. Dessa forma, a fantasia de parcela da população brasileira de identificação com o europeu é mantida por meio da incorporação do seu sistema jurídico (liberal, moderno e ocidental).

Entretanto, Souza (1999) assinala que essa situação revela o funcionamento de outra fantasia que dá conta da manutenção da representação identitária calcada apenas no trabalho do pensamento, excluindo-se, assim, a realidade constituída pelas experiências nacionais, particularmente, a experiência da escravidão. Assim, a sociedade brasileira foi estruturada pela demanda da igualdade expressa na tentativa de parcelas da população em responder criativamente à Constituição Federal, adaptando o ideário do liberalismo à experiência nacional da escravidão, reconhecendo e incorporando a realidade nacional. Nesse caso, a base das experiências brasileiras primou pela busca da articulação da vivência da identidade à existência à medida que foi construindo práticas sociais específicas voltadas ao funcionamento de uma ampla rede social.Todavia, tais práticas explicitariam, ao que parece, o princípio da igualdade não como sintoma associado à repetição da fantasia de equiparação do europeu, por in- 
termédio do artifício da negação da realidade e da singularidade nacional. $\mathrm{Na}$ verdade, essas práticas sociais revelariam a criação de uma economia moral.

O caso do "jeitinho brasileiro" é revelador de como um sintoma ${ }^{14}$ pode ter-se articulado, originariamente, à ordem da criação, respondendo à excessiva burocracia e ao legalismo nacional. Contudo, no momento em que passa a constituir-se em elemento da identidade nacional, sendo associado à transgressão e referendando a valorização da afetividade e da cordialidade, como elementos substitutivos da igualdade, é utilizado respondendo a outras situações e cristalizando o funcionamento social dissociado, presente na sociedade brasileira. Assim, por um lado, essa prática social revela sua criatividade quando explicita a produção das subjetividades por meio das quais procura lidar com a realidade presente em nossa sociedade, ou seja, com a dissociação entre representação e funcionamento do país; por outro, porém, revela a repetição presente na manutenção de práticas e subjetividades caracterizadas pela dissociação entre lei formal e informal.

Recebido em 06.10.2005. Aprovado em 24.11.2005.

\section{Referências}

BOURDIEU, P. O poder simbólico. Lisboa: Difel, 1989.

Coisas ditas. São Paulo: Brasiliense, 1990.

A economia das trocas simbólicas. São Paulo: Editora Perspectiva, 1992.

A economia das trocas lingüisticas: o que falar quer dizer. São Paulo: Edusp, 1996.

BERNARDI, D.C.F. Histórico da inserção do profissional psicólogo no Tribunal de Justiça do Estado de São Paulo - um capítulo da psicologia jurídica no Brasil. In: BRITO, L.M. T. Temas de psicologia jurídica. Rio de Janeiro: Relume Dumará, 1999, p. 19-28.

CARVALHO, J. M. A construção da ordem: a elite política imperial. Brasília: UnB, 1981.

CENTURIÃO, L. R. M. A cidade colonial no Brasil. Porto Alegre: Edipucrs, 1999.

COSTA, S. de S. G. Subjetividade e menor-idade: acompanhando o devir dos profissionais do social. São Paulo: Annablume; Fortaleza: Secretaria da Cultura e Desporto, 1998.

DAMATTA, R. Brasil: uma nação em mudança ou uma sociedade imutável? Considerações sobre a natureza do dilema brasileiro. Estudos Históricos. Rio de Janeiro: FGV, v. 1, n. 2, p. 204-219, 1988,

Carnavais, malandros e heróis: para uma sociologia do dilema brasileiro. Rio de Janeiro: Guanabara, 1992.

Conta de mentiroso: sete ensaios de antropologia brasileira. Rio de Janeiro: Rocco, 1993.
FAORO, R. Os donos do poder: formação do patronato político brasileiro. Porto Alegre: Globo, 1976.

FREUD, S. Leccion XVII. El sentido de los sintomas. Madrid. Ed. Biblioteca, 1973.

FIGUEIREDO, L.C. Modos de subjetivação no Brasil. São Paulo: Escuta, 1995.

GAGLIETTI, M. O discurso jurídico como articulador da "sociedade". Serviço Social \& Sociedade, São Paulo: Cortez, n. 60, p. 83-91, 1999.

PT: ambivalências de uma militância. 2. ed. Porto Alegre: DaCasa/Palmarinca, 2003.

HOLANDA, S. B. de. Raízes do Brasil. Rio de Janeiro: José Olympio, 1979.

ROLNIK, S. Esquizoanálise e antropofagia. Cadernos de Subjetividade. São Paulo: Hucitec, v. 1, n. 04, p. 89, 1996.

SCHWARTZMAN, S. Bases do autoritarismo brasileiro. Brasília: Universidade de Brasília, 1982.

SOUZA, M. de. A sociedade disciplinar, a opinião pública e o jornal. Cadernos de Subjetividade, São Paulo: Hucitec, v. 1, n. 04, p. 269-279, 1996.

- A experiência da lei e a lei da experiência: ensaios sobre práticas sociais e subjetividades no Brasil. Rio de Janeiro: Revan; São Paulo: FAPESP, 1999.

URICOECHEA, F. O minotauro imperial. São Paulo: Difel, 1978.

THOMPSON, E. P. Tradición, revuelta y consciencia de clase. Barcelona: Grijalbo, 1979.

WARAT, L. A. Introdução geral ao Direito: a epistemologia jurídica da modernidade. Porto Alegre: Sérgio Fabris Editor, 1995.

\section{Notas}

1 Conforme Thompson (1979), o conceito de economia moral, no seu estudo sobre a sociedade inglesa préindustrial do século XVIII, tem origem nos chamados "motins alimentares", ocorridos no período examinado. Ele entende esses movimentos como práticas complexas, marcadas por ações diretas, disciplinadas e com objetivos determinados. Caracterizava-os, ainda, a presença de uma economia moral que apontava para a existência de valores transmitidos de geração a geração, que se impunham, resultando, em casos extremos, na ação direta da multidão. A intenção dos motins alimentares era a fixação dos preços, e o autor relata dezenas de casos, nos quais a população saqueava e se apoderava de grãos e sacos de farinha, necessários à preparação do pão que se constituía, principalmente nos anos de escassez, no seu principal alimento, forçando o proprietário a vendê-los ao preço estipulado. Essa prática revelaria a existência de uma economia moral, construída e exercida pela multidão. Essa economia funcionaria dentro dos limites do possível, no caso, limites demarcados pela tradição, e explicitaria a adoção de uma legislação interna e informal, operando por meio dessas práticas. 
2 A autora problematiza a aplicação desse princípio nas práticas do "jeitinho" e do "favor" (a partir da interpretação que faz de uma ampla bibliografia da sociologia dos dilemas brasileiros levantada por Roberto DaMatta, Livia Barbosa, Vianna Moog, Sérgio Buarque de Holanda e Gilberto Freyre). O "jeitinho" explicita tanto uma das versões nacionais de apropriação do projeto liberal e do princípio da igualdade, como o funcionamento da economia moral de grande parte da população. O "favor", como também veremos a seguir, explicita uma outra versão desse projeto e outro funcionamento moral presente no Brasil. De qualquer forma, a autora ressalta que a análise dessas práticas sociais pode ajudar-nos a compreender o funcionamento da demanda da igualdade, conforme estabelecida no país e, também, pode explicitar o significado assumido por essas práticas e sua relação com o funcionamento de uma economia moral produzida e exercitada pela maioria dos brasileiros (SOUZA, 1996, p. 269-279; 1997, p. 53-64).

3 De acordo com Costa (1998, p. 15-25), os profissionais do social são atores sociais e agentes institucionais ligados às profissões do trabalho social, ou seja, um amplo campo de ação profíssional que se estende da Psicologia ao Serviço Social, englobando a Sociologia e ramificando-se numa série de atividades técnico-assistenciais e de cunho clínico, tais como Fonoaudiologia, Terapia Ocupacional e todo o trabalho em torno do lúdico.

4 O reconhecimento da Psicologia Jurídica como uma especialidade, pelo Conselho Federal de Psicologia, pode, por um lado, sugerir que os profissionais dessa área construíram uma prática e acumularam um saber específico sobre a realidade particularizada no contexto judicial das Varas da Infância e Juventude e Varas de Família e das Sucessões. Por outro, pode reconhecer nessa especificidade aquilo que os identifica como profissionais de uma Psicologia - talvez aquela que se proponha a ver na subjetividade de cada pessoa os atravessamentos de classe, gênero, raça e idade dessa sociedade moderna. Assim, a Psicologia Judiciária, mais que um nome a definir lugar, tem sido um espaço amplo e contraditório, no qual os profissionais da área inscrevem suas ações e, com elas, todo um dispositivo de saber que, ao ser construído por eles, os constrói a todos.

5 Denominação dada pela própria instituição judiciária ao seu respectivo quadro funcional.

6 Utilizam-se aqui as noções poder simbólico, campo jurídico, campo político e habitus formuladas por Pierre Bourdieu $(1989,1990,1992,1996)$.

7 O campo é o lugar em que se geram - na concorrência entre os agentes que nele se acham envolvidos - produtos, problemas, programas, análises, comentários, conceitos e acontecimentos. Tais produtos também geram os cidadãos comuns, reduzidos ao estatuto de "consumidores", que, ao se relacionarem com um dos aspectos da concorrência, de certa forma, tendem a interpretar diferentemente as designações utilizadas pelos profissionais que articulam o funcionamento do campo (BOURDIEU, ibid.).

8 O habitus é a disposição incorporada na ação prática dos agentes sociais. Em conseqüência, forma-se um conhecimento prático que é adquirido por meio da experiência de vida. Esse capital estrutura-se a partir das estratégias formuladas pelos agentes em ação. Bourdieu chama a atenção para o primado da razão prática. O habitus constitui um princípio gerador que tende a reproduzir as regularidades inscritas nas condições objetivas e estruturais que presidem o próprio princípio gerador. Ao mesmo tempo, permite adequações e transformações inovadoras diante das demandas do cotidiano, colocando em prova, assim, a sua eficácia. É esse processo que confere à práxis social um espaço de incertezas e de liberdade que, mesmo limitado pelos aspectos estruturais objetivos - aos quais deve a sua existência -, encerra as potencialidades objetivas de inovação e transformações sociais. Destacase, por fim, que o habitus fecha o circuito de internalização de estruturas exteriores, à medida que as práticas dos agentes exteriorizam os sistemas de disposições incorporadas (BOURDIEU, ibid.).

9 O poder simbólico é exercido com a cumplicidade daqueles que não querem saber que lhe estão sujeitos ou mesmo que o exercem. Esse poder é um eficaz instrumento de conhecimento e de construção do mundo dos objetos. Portanto, é a partir dele que se instala o aspecto ativo do conhecimento. Formata uma concepção homogênea - tempo, espaço, número e causa - que torna possível um consenso entre as inteligências. $O$ poder simbólico é um poder de construção da realidade que tende a estabelecer o sentido imediato do mundo social na medida em que o coesiona socialmente. Tal integração se dá em função da utilização de um competente sistema de símbolos. É dessa forma que os sistemas simbólicos cumprem uma função política ao se constituírem como instrumentos de imposição ou de legitimação da dominação.

10 A modernidade é entendida como processo fundado na crença no potencial da razão emancipatória dos povos e no progresso da ciência - no momento da sua adequação ao Brasil. Nesse caso, teríamos de pensar em outras possibilidades de articulação e funcionamento das leis na sociedade nacional. Usar de outros modelos interpretativos que não os adotados por sociedades, marcadas pelo "individualismo e impessoalidade", nas quais encontramos o projeto da cisão entre o público e o privado, com a aplicação impessoal das leis, delegada ao primeiro. Assim, teríamos, com base nesse contexto, a produção de subjetividades que articulam a vivência da lei de forma distinta daquela produzida nas e pelas sociedades modernas. Em outros termos, há uma presença, no caso brasileiro, de um padrão de sociabilidade muito distinto do europeu moderno, padrão no qual o "pai" comparece de outra forma (FIGUEIREDO, 1995, p. 91). Na mesma linha de argumentação, Rolnik (1996, p. 89) também encaminha para o reconhecimento do "desejo conduzido pela lei da antropofagia", levando-o a ignorar a positividade da lógica presente nesse desejo e a interpretálo "como carecendo de uma associação à lei abstrata do ideal transcendente e à lei negativa da falta, submetido exclusivamente à regra do prazer que o pontua de fora. Tal funcionamento será diagnosticado como traço transgressivo próprio de uma posição arcaica na suposta escala do desenvolvimento psíquico e/ou cultural." 
11 Ver DaMatta $(1988,1992,1993)$ e Souza (1999).

12 A tradição não está instalada no fato social. Deve-se considerar que a tradição, por si, não existe. Uma prática social não é tradicional em si, mas é tradicionalizada, dentro de um quadro de reinterpretação simbólica. A tradição é um atributo superposto, agregado de modo arbitrário a qualquer evento, desde que este esteja inscrito, como ocorre forçosamente, na temporalidade. É isso que se "presentifica". Se não fosse assim, teríamos de admitir que o passado pode ser revivido. Contudo, o passado só existe enquanto presente, o que é um modo de não existir, só pode ser vivido ao modo do presente. Assim, uma suposta "marca do passado" só pode ser um elemento do presente, portanto não do passado. No entanto, a reificação ou fundamentalização de práticas ou eventos pretéritos permite que o presente torne a condição de facticidade sem fundamento para, a partir daí, adquirir sentido (CENTURIÃO, 1999).

$13 \mathrm{O}$ conceito de patrimonialismo aplicado à história brasileira não pode ser percebido como o prolongamento de uma "tradição", muitas vezes associada à ausência de modernização econômica e social. Embora a referida concepção auxilie em muito no entendimento das particularidades brasileiras, não dá conta, sozinha, de abarcar todos os aspectos que envolvem o Estado. Isso significa negar a experiência histórica que introduziu cunhas nas estruturas estatais, mediando o próprio exercício do "patrimonialismo puro", que, mesmo em termos weberianos, não existiu no Brasil. O traço mais relevante é a particularidade do Estado brasileiro não ser estranho à sociedade. O Estado patrimonial, tido como "tradicional", representando a principal alavanca de "modernização", o que, muitas vezes, dificultou a implementação dos interesses dos segmentos dominantes (URICOECHEA, 1978; CARVALHO, 1981; SCHWARTZMAN, 1982; HOLANDA, 1979; FAORO, 1976). A própria polarização "tradicional" versus "moderno", intrínseca aos modelos teóricos que definem o patrimonialismo, não deve ser transplantada para a experiência histórica brasileira de forma automática. A caracterização do Estado brasileiro como "patrimonial" não pode ser percebida como a continuidade e/ou persistência de uma "tradição", muitas vezes associada à ausência de modernização econômica e social. Assim, ainda que a construção do Estado brasileiro tenha sido, inevitavelmente, afetada pela experiência portuguesa do patrimonialismo, o processo ocorrido no país, foi muito dinâmico e assumiu, por vezes, um caráter às vezes "indeterminado".

14 A respeito da discussão sobre a formação dos sintomas e suas funções, recorrer a Freud (1973, p. 2282-2292). O autor salienta que todo sintoma constituiu-se originariamente como criação, porém, o problema reside na manutenção da resposta articulada pelo sintoma e do seu deslocamento para outras situações e contextos.

\author{
Mauro Galietti \\ ifch@upf.br \\ secfac@upf.br \\ maurogaglietti@upf.br
}

Universidade de Passo Fundo - UPF

Instituto de Filosofia e Ciências Humanas - IFCH

Bairro São José, BR 285 - Km 171

Caixa Postal 611

Passo Fundo - Rio Grande do Sul

CEP: 99001-970 